\title{
CARACTERIZAÇÃO FÍSICO-QUÍMICA DE FRUTOS DE MARACUJAZEIRO-AMARELO SUBMETIDOS À ILUMINAÇÃO ARTIFICIAL, IRRIGAÇÃO E SOMBREAMENTO'
}

\author{
JOSÉ CARLOS CAVICHIOLI ${ }^{2}$, CARLOS RUGGIERO ${ }^{3}$, CLOVIS ALBERTO VOLPE $^{4}$
}

RESUMO - O presente trabalho objetivou avaliar alguns parâmetros físico-químicos de frutos de maracujazeiro-amarelo (Passiflora edulis Sims f. flavicarpa Deg) submetidos a diferentes sistemas de produção. Avaliaram-se o peso, o comprimento, o diâmetro, o teor de sólidos solúveis (SS) e a acidez titulável (AT) dos frutos, a relação SS/AT, o peso e o rendimento da polpa, a espessura da casca e o rendimento de suco. Compararam-se quatro sistemas de produção (iluminação artificial/irrigação/sombreamento, iluminação artificial/irrigação, iluminação artificial/sombreamento, iluminação artificial) e um tratamento-testemunha, em condições naturais. Os tratamentos foram submetidos a três diferentes épocas de iluminação (12 de abril, 27 de abril e 12 de maio). O experimento foi conduzido na área da Escola Técnica Agrícola de Adamantina - SP, na região da Alta Paulista, no período de abril a dezembro de 1997. Observou-se que, no período de junho a novembro, os diferentes sistemas de produção e as épocas de iluminação não alteraram o peso, o comprimento e o diâmetro médio dos frutos de maracujazeiro. A iluminação artificial, a irrigação e o sombreamento não influenciaram no teor de sólidos solúveis e na acidez dos frutos. Os frutos colhidos em agosto apresentaram teores de brix e de acidez maiores que os colhidos em dezembro. No mês de dezembro, no ambiente iluminado, irrigado e sombreado, verificou-se aumento do peso médio dos frutos, do peso da polpa e da espessura da casca, apesar de apresentarem menor produção. Em condições naturais, observou-se menor peso de frutos e de polpa, mas aumento no rendimento da polpa e do suco. O sombreamento artificial, na ausência de irrigação, promoveu a redução no peso e no rendimento de polpa e de suco.

Termos de indexação: maracujá-amarelo, fotoperíodo, propriedades físicas, propriedades químicas, qualidade dos frutos.

\section{PHYSICALAND CHEMICAL CHARACTERISTICS OF YELLOW PASSION FRUIT SUBMITTED TO THE ARTIFICIAL LIGHTING, IRRIGATION AND SHADE}

\begin{abstract}
The aim of this work was to evaluate some physical and chemical characteristics of the yellow passion fruit (Passiflora edulis Sims f. flavicarpa Deg.) submitted to artificial light, irrigation and shade. It was evaluated the mass, length, diameter, soluble solids and the acidity of the fruits, the soluble solids/acid ratio, the weight and the percentage of the pulp, thickness of the peel and the juice yield. Four systems of production were compared: artificial light/irrigation/shade; artificial light/irrigation; artificial light/ shade, artificial light and a natural condition system. The treatments were submitted to artificial light in three different seasons: April $12^{\text {th }}$, April $27^{\text {th }}$ and May 12 $2^{\text {th }}$. The experiment was carried out at Escola Técnica Agrícola de Adamantina, SP, Brazil, from April to December 1997. It was observed that in the period from June to November, the different systems of production did not modify the average weight, length and diameter of the fruits of the yellow passion fruit. The artificial light, the irrigation and the shade did not affect the soluble solids content and the acidity of the fruits. The fruits produced in August presented soluble solids and acidity higher than the fruits produced in December. In December, in the illuminated, irrigated and shadowed environment, it was observed an increase in the average weight of the fruits, in the weight of the pulp and thickness of the peel, although there was a lower production. The absence of light, irrigation and shade decreased the weight of fruits and pulp, but increased the juice and pulp yield. The shade, in the irrigation absence decreased the weight and the juice and pulp yield.
\end{abstract}

Index terms: yellow passion fruit, photoperiod, chemical properties, physical properties, fruit quality.

1(Trabalho 250-07). Recebido em: 19-10-2007. Aceito para publicação em: 10-04-2008.Parte da dissertação de mestrado do primeiro autor. Projeto financiado pela FAPESP.

${ }^{2}$ Pesquisador da APTA Alta Paulista, Caixa Postal 191, 17.800-000, Adamantina-SP.Fone: (18) 3521-4800. jccavichioli@apta.sp.gov.br, com bolsa de mestrado do CNPQ.

${ }^{3}$ Professor Titular de Fruticultura, do Departamento de Produção Vegetal, FCAV-UNESP, ruggiero@fcav.unesp.br

${ }^{4}$ Professor Adjunto do Departamento de Ciências Exatas, FCAV-UNESP, cavolpe@fcav.unesp.br 


\section{INTRODUÇÃO}

O maracujazeiro apresenta grande importância no setor agrícola, devido às características físico-químicas e fármacoterapêuticas dos frutos.

O Brasil é o maior produtor mundial e apresenta uma produção de 491 mil toneladas em uma área de aproximadamente 36.500 ha (Agrianual, 2006). O maracujá-azedo representa 97\% da área plantada e do volume comercializado em todo o País, com $60 \%$ da produção destinada ao consumo in natura, e o restante, destinado às indústrias de processamento, sendo o suco o principal produto (Fracaro, 2004).

No Estado de São Paulo, a cultura do maracujá tem sido uma alternativa bastante atraente para pequenos produtores, a maioria no contexto de agricultura familiar. O Estado, que, em 1997, apresentava uma área cultivada de 4.000 ha, teve uma redução para 2.600 ha em 2004 (Agrianual, 2006) devido a problemas de ordem fitossanitário, como fungos de raízes, doenças de folhas e viroses.

No mercado interno, os maiores preços da fruta para consumo in natura são obtidos nos meses de agosto a outubro, quando há menor oferta do produto. A produção na entressafra (agosto a novembro) irá depender da indução floral, da temperatura do ar e da disponibilidade de água no solo.

O comprimento do dia e a temperatura do ar são considerados os fatores ambientais mais importantes para o controle do florescimento (Taiz \& Zeiger, 1991). O maracujazeiroamarelo é considerado uma planta de "dias longos", recomendando-se 12 horas de luz para florescer (Piza Junior, 1993). A iluminação artificial pode ser aplicada com a finalidade de prolongar o comprimento do dia (fotoperíodo), permitindo o controle do florescimento (Philips, 1989 e IES, 1981). Cavichioli et al. (2006) verificaram que a iluminação artificial promoveu aumento no número de frutos e na produção por área do maracujazeiro-amarelo.

O estresse hídrico durante o desenvolvimento do fruto pode levar a decréscimos no peso e no volume de polpa, murcha e, por fim, à queda dos frutos (Teixeira et al., 1990). A irrigação influencia na produtividade, no peso médio, no comprimento e no diâmetro dos frutos, recomendando-se, em pomares de maracujá, manter o perfil de umidade do solo próximo à capacidade de campo, principalmente durante o florescimento (Menzel et al., 1986).

Em São Paulo, a maioria da comercialização visa ao mercado de frutas frescas, realizada principalmente junto ao CEASA. As vendas diretas aos supermercados e redes varejistas têm-se ampliado significativamente, reduzindo a participação dos mercados atacadistas. Nesse mercado, os frutos são entregues necessariamente classificados, que se baseia em seu tamanho (Meletti, 2001).

As características externas do fruto constituem os parâmetros primordiais avaliados pelos consumidores e devem atender a certos padrões para que atinjam a qualidade desejada na comercialização. Os consumidores, em geral, preferem frutos maiores, de aparência atraente, mais doces e menos ácidos, quando destinados ao consumo in natura. Na indústria de suco, há preferência por frutos de alto rendimento em suco e com maior teor de sólidos solúveis totais (Nascimento, 1996).

O presente trabalho teve por objetivo avaliar algumas características físico-químicas de frutos de maracujazeiro-amarelo submetidos à iluminação artificial, irrigação e sombreamento.

\section{MATERIAL E MÉTODOS}

O experimento foi conduzido na área da Escola Técnica Agrícola "Eng ${ }^{\circ}$ Herval Bellusci" de Adamantina-CEETEPS, na região da Nova Alta Paulista ( $453 \mathrm{~m}$ de altitude, $21^{\circ} 42^{\prime}$ 'S de latitude e $51^{\circ} 08^{\prime} \mathrm{W}$ de longitude), no período de abril a dezembro de 1997. $\mathrm{O}$ solo da área experimental foi classificado como Argissolo Vermelho-Amarelo, eutrófico, A moderado, textura arenosa/média e apresenta uma topografia ondulada.

O clima da região é do tipo Cwa, com estação chuvosa no verão e estação seca no inverno. A precipitação média anual é de $1.300 \mathrm{~mm}$. A temperatura média anual está em torno de $22-23^{\circ} \mathrm{C}$, a do mês mais quente em torno de $26^{\circ} \mathrm{C}$, a do mês mais frio está por volta de $17-18^{\circ} \mathrm{C}$. A média da temperatura máxima está ao redor de $29^{\circ} \mathrm{C}$, enquanto a média da temperatura mínima é em torno de $17^{\circ} \mathrm{C}$.

O espaçamento adotado foi de $4 \mathrm{~m}$ entre plantas por 3,5 $\mathrm{m}$ nas entrelinhas, as quais foram orientadas no sentido nortesul. O processo de condução foi o de espaldeira, com um único fio de arame liso, fixo em mourões de 2,0 m de altura do nível do solo, espaçados de $8 \mathrm{~m}$, intercalados com bambu. O delineamento experimental foi de blocos completamente casualizados, em parcelas subdivididas, com quatro repetições. Os tratamentos corresponderam a quatro sistemas de produção: iluminação artificial/irrigação/sombreamento, iluminação artificial/irrigação, iluminação artificial/sombreamento, iluminação artificial e um tratamento-testemunha, em condições naturais, que foram alocados nas parcelas, e de três épocas de iluminação: 12 de abril, 27 de abril e 12 de maio, que foram alocadas na subparcela. Iluminou-se um dos lados da espaldeira com lâmpadas incandescentes de $100 \mathrm{~W}$ (consumo). Foram utilizadas duas lâmpadas para cada subparcela iluminada, ou seja, a cada oito metros, colocadas a 1,5 m do solo, fixadas em mourões e afastadas perpendicularmente a 1,0 $\mathrm{m}$ da espaldeira (Figura 1).

Iniciou-se o prolongamento do dia com iluminação artificial a partir do dia 12 de abril de 1997 (época 1), quando a cultura se encontrava com cinco meses de idade, no dia 27 de abril (época 2) e no dia 12 de maio (época 3), visando a atingir $12 \mathrm{~h}$ de luz/dia, e estendeu-se até o dia 16 de setembro de 1997, quando o fotoperíodo passou a ser de 12 horas. Nas épocas citadas, os fotoperíodos são, respectivamente, de $11 \mathrm{~h} 7 ; 11 \mathrm{~h} 4$ e $11 \mathrm{~h} 2$. Acrescentaram-se 30 minutos no fotoperíodo, em função do crepúsculo vespertino, ou seja, meia hora antes do ocaso do sol ainda há luz, que possui indução fotoperiódica (Francis, 1970).

O método de irrigação utilizado foi o de microaspersão. A instalação dos microaspersores foi feita nas linhas de plantio, trabalhando a uma pressão de serviço de 15 m.c.a e apresentando uma vazão de $261 \cdot h^{-1}$. Utilizou-se um turno de rega de três dias, 
sendo que as lâminas aplicadas foram determinadas de acordo com a evapotranspiração de referência $\left(\mathrm{ET}_{0}\right)$, obtida da multiplicação da evaporação do tanque Classe A pelo Kp adotado, que foi de 0,75. Multiplicou-se o valor de $\mathrm{ET}_{0}$ por 0,7, que foi o Kc adotado de acordo com Lopes (1995). Toda vez que a chuva excedia os valores da evaporação no tanque, a irrigação era suspensa. Os índices de precipitação foram obtidos na Escola Técnica Agrícola, e os de evaporação, pelo tanque Classe A, obtidos na Estação Agrometeorológica do Instituto Agronômico - CIIAgro, localizada junto ao Pólo Regional de Desenvolvimento Tecnológico dos Agronegócios da Alta Paulista, em Adamantina, distante a $2 \mathrm{~km}$ do local do experimento. Utilizando-se dos dados de precipitação pluvial e da temperatura média do ar, efetuou-se o cálculo do balanço hídrico (Figura 2), com base no método de Thornthwaite \& Mather (1955), considerando-se a capacidade de retenção de água no solo de $100 \mathrm{~mm}$.

Para os tratamentos sombreados, foi utilizada cobertura com tela de polipropileno (sombrite), fator de sombra $30 \%$, de cor preta, colocada em uma estrutura com $2,5 \mathrm{~m}$ de altura $(50 \mathrm{~cm}$ acima da espaldeira, e as laterais a $50 \mathrm{~cm}$ da altura do solo), e dois metros de largura, de forma a proteger a espaldeira.

Avaliaram-se o peso, o comprimento e o diâmetro médio dos frutos no período de junho a novembro; o teor de sólidos solúveis (SS), a acidez titulável (AT) e a relação SS/AT nos meses de agosto e dezembro; o peso de fruto, o peso e o rendimento de polpa, a espessura da casca e o rendimento de suco, no mês de dezembro.

Peso médio dos frutos: coletou-se mensalmente uma amostra de dez frutos/subparcela, pesando-se individualmente os mesmos com uma balança de precisão $0,1 \mathrm{~g}$.

Diâmetro e comprimento médio dos frutos: coletou-se mensalmente uma amostra de dez frutos/subparcela, medindoos com auxílio de um paquímetro de precisão $0,1 \mathrm{~mm}$.

Determinação de sólidos solúveis (SS), acidez titulável (AT) e relação SS/AT: foram realizadas no laboratório de horticultura da FCAV-UNESP, Jaboticabal. O teor de sólidos solúveis (SS) foi obtido pela leitura direta em um refratômetro manual com os resultados expressos em ${ }^{\circ}$ Brix, e a acidez titulável foi determinada através de titulação com uma solução $0,1 \mathrm{~N}$ de $\mathrm{NaOH}$, expressa em porcentagem de ácido cítrico.

A relação SS/AT foi obtida pela divisão direta dos sólidos solúveis pela acidez titulável.

Para a avaliação do peso do fruto no final do experimento, foram coletados cinco frutos maduros por subparcela, aleatoriamente, no dia 23-12-97. Os frutos foram colocados em sacos plásticos perfurados e levados para o laboratório, pesando-se individualmente os mesmos com uma balança de precisão $0,1 \mathrm{~g}$.

Peso e rendimento de polpa: após a pesagem dos frutos, a polpa foi retirada com uma colher e acondicionada em um béquer para a determinação do peso e rendimento. Utilizou-se de uma balança de precisão $0,1 \mathrm{~g}$. O rendimento da polpa foi determinado pela relação do peso da polpa com o peso do fruto.

Espessura da casca: após o corte dos frutos e a retirada da polpa, mediu-se a espessura da casca, com o auxílio de um paquímetro Mitutoyo de precisão $0,1 \mathrm{~mm}$.

Separação do suco: logo após a extração da polpa, esta foi colocada em um liqüidificador doméstico e ligado por aproximadamente dois segundos, intermitentemente, para a extração do suco sem a destruição das sementes. Em seguida, todo o conteúdo foi colocado em uma peneira de náilon de malha fina para a separação das sementes.

A análise de variância dos dados foi realizada segundo o procedimento PROC GLM do pacote estatístico SAS, versão 8.0 para Windows. Todos os conjuntos de dados foram testados, antes da análise geral, com a finalidade de assegurar que as quatro prerrogativas básicas da análise de variância (aditividade do modelo, independência dos erros, normalidade dos dados e homogeneidade das variâncias) estavam sendo respeitadas.

\section{RESULTADOS E DISCUSSÃO}

Os resultados de peso, comprimento e diâmetro médio dos frutos são apresentados na Tabela 1. Verifica-se que, no período de junho a novembro, não houve efeito dos tratamentos e das épocas de iluminação no peso, no comprimento e no diâmetro médio dos frutos. Isso mostra que a irrigação não aumentou o peso e o tamanho dos frutos, o que pode ser explicado pelos excedentes hídricos observados durante o período de experimentação (Figura 2). Observa-se que, no mês de junho, ocorreu um excedente hídrico, excessivamente atípico para o município, minimizando assim os efeitos dos tratamentos nãoirrigados. O peso médio dos frutos variou de $144,24 \mathrm{~g}$ (iluminado/ sombreado) a 149,83 g (iluminado/irrigado/ sombreado), estando os mesmos acima dos valores encontrados por Nascimento (1996) e por Fortaleza et al. (2005).

O comprimento e o diâmetro são índices físicos de grande utilidade para frutos destinados ao mercado, sendo de uso restrito quando destinados ao processamento. O comprimento médio variou de $7,57 \mathrm{~cm}$ (iluminado/irrigado/sombreado) a $7,81 \mathrm{~cm}$ (iluminado/sombreado). Esses resultados foram superiores aos encontrados por Sjostrom \& Rosa (1978), dentro da faixa citada por Nascimento (1996). O diâmetro médio dos frutos variou de $6,87 \mathrm{~cm}$ (iluminado/irrigado) a $6,95 \mathrm{~cm}$ (iluminado/irrigado/ sombreado, iluminado/sombreado e iluminado), resultados superiores aos encontrados por Sjostrom \& Rosa (1978) e dentro da faixa citada por Nascimento (1996). Os consumidores, em geral, preferem frutos maiores, de aparência atraente quando destinados ao mercado in natura.

Nas Figuras 3; 4 e 5, são apresentados os teores de sólidos solúveis (SS), os da acidez titulável (AT) e da relação SS/ AT de frutos de maracujazeiro-amarelo submetidos à iluminação artificial, irrigação e sombreamento. O teor de sólidos solúveis é um parâmetro que tem sido utilizado como indicador da qualidade dos frutos. Não houve diferenças entre os sistemas de produção para sólidos solúveis e acidez ( $\mathrm{P}>0,01)$, no entanto frutos colhidos em agosto apresentaram teores de sólidos solúveis e de acidez superiores aos colhidos em dezembro $(\mathrm{P}<0,01)$. Os teores de sólidos solúveis encontrados foram de $14,3^{\circ}$ Brix em agosto e de $10,6^{\circ}$ Brix em dezembro (Figura 3), dentro da faixa encontrada por 
Teixeira et al. (1990) e menores que aqueles obtidos por Borges et al. (2003). Além dos efeitos genéticos, outros fatores, como temperatura, água, adubação e luz, determinam o nível de fotossíntese da planta, e, conseqüentemente, a quantidade de açúcares e matéria seca disponível para os frutos (Pierrô, 2002).

Diversos trabalhos relacionam parâmetros de qualidade do fruto com as condições climáticas. Utsunomiya (1992) observou que o teor médio de açúcares foi maior em temperaturas diurnas/noturnas intermediárias de $28 / 32^{\circ} \mathrm{C}$, quando comparadas com temperaturas de $33 / 28^{\circ} \mathrm{C}$.

$\mathrm{O}$ teor de acidez variou de $3,5 \mathrm{em}$ agosto a $2,3 \mathrm{em}$ dezembro (Figura 4), valores inferiores aos encontrados por Borges et al. (2003). Altos teores de ácidos no suco revelam uma característica importante no que diz respeito ao processamento, pois é interessante que os frutos possuam elevada acidez, visto que isso diminuiria a adição de acidificantes no suco (Nascimento, 1996). No entanto, para mercado in natura, são preferidos frutos mais doces e menos ácidos. $\mathrm{O}$ aumento na acidez em frutos colhidos sob baixas temperaturas e radiações também foi observado por Sjostrom \& Rosa (1978) e por Ritzinger et al. (1989).

O ácido cítrico é o ácido mais acumulado no fruto, começando a acumular logo após a formação do fruto e rapidamente alcança o valor máximo. As condições nutricionais e, particularmente, a temperatura são fatores que mais influenciam no acúmulo desse ácido. Após alcançar o valor máximo, a concentração desse ácido decresce. O decréscimo na concentração, durante a maturação, é parcialmente devido ao aumento do tamanho do fruto, pela absorção de água, com a diluição do ácido e da taxa respiratória, que é dependente da temperatura. Quanto maior a temperatura durante a maturação, maior é o decréscimo da concentração de ácidos (Rasmussen et al., 1966; Albrigo, 1992). Assim, os frutos colhidos em agosto, que foram formados no inverno, tiveram uma soma de temperaturas provavelmente mais diretamente relacionada ao crescimento do fruto e, conseqüentemente, ao aumento da capacidade do mesmo em absorver e reter água, que, por sua vez, provocou a diluição do ácido. Por outro lado, as elevadas temperaturas de outubro e novembro podem ter excedido o ponto de compensação, quando a demanda respiratória é alta, diminuindo assim a reserva do ácido cítrico das células do suco.

A iluminação, a irrigação e o sombreamento não interferiram na relação sólidos solúveis/acidez titulável $(\mathrm{P}>0,01)$, como pode ser constatado na Figura 5. Essa relação também não diferiu para as duas épocas avaliadas, variando de 4,21 para frutos colhidos em agosto a 4,61 para frutos colhidos em dezembro.

Os resultados com peso médio de frutos, peso e rendimento de polpa, espessura da casca e rendimento de suco estão na Tabela 2. Observa-se que os sistemas de produção influenciaram no peso dos frutos colhidos em dezembro. Os frutos mais pesados foram obtidos no tratamento iluminado/irrigado/ sombreado, com 173,58 g, diferindo apenas dos frutos do tratamento-testemunha, que pesaram 131,66 g. O fator sombra, associado à irrigação e iluminação, favoreceu o ganho de peso no maracujá. $\mathrm{O}$ maior peso de polpa também foi obtido no tratamento iluminado/irrigado/sombreado, com 89,62 g, diferindo dos tratamentos iluminado/sombreado e do tratamentotestemunha, que apresentaram, respectivamente, 67,22 e 69,14 g. A menor radiação no ambiente sombreado foi compensada pelo fator água, que é de fundamental importância na translocação de nutrientes nos processos de absorção por fluxo de massa e difusão (Malavolta et al., 1989).

Frutos de maracujá são preferidos quando possuem casca mais fina, pois apresentam maior quantidade de polpa. Os frutos do tratamento iluminado/irrigado/sombreado apresentaram a maior espessura de casca, que diferiu do tratamento iluminado/ irrigado, só iluminado, e do tratamento sem iluminação, irrigação e sombreamento. As espessuras de casca variaram de 5,45 a 6,66 $\mathrm{mm}$, situando-se dentro da faixa encontrada por Nascimento (1996). O sombreamento, associado à irrigação, favoreceu o aumento na espessura da casca. O menor rendimento de polpa foi observado no tratamento iluminado/sombreado, que diferiu dos demais sistemas. Os valores encontrados oscilaram de 45,21 a $54,65 \%$, encontrando-se dentro da faixa daqueles citados por Costa et al. (2001), compatíveis para o mercado in natura e para a industrialização.

O rendimento em suco é de grande importância na indústria de sucos e está associado ao teor de sólidos solúveis, para uma melhor avaliação da matéria-prima. Apesar de o tratamento com ausência de iluminação, irrigação e sombreamento apresentar menor peso de fruto e menor peso de polpa, ele apresenta um rendimento de polpa e de suco comparado aos melhores tratamentos, o que pode ser explicado pela menor espessura de casca apresentada neste tratamento. $\mathrm{O}$ sombreamento artificial, na ausência de irrigação, promoveu redução no peso e no rendimento de polpa e de suco. O rendimento de suco variou de $29,25 \%$ no sistema iluminado/ sombreado a $34,94 \%$ no sistema iluminado, valores que estão acima daqueles encontrados por Nascimento (1996).

A espessura de casca correlacionou-se significativa e negativamente ao rendimento de polpa e de suco, obtendo-se, respectivamente, os coeficientes $r=-0,76$ e $r=-0,68$ (Figura 6). De acordo com as equações de ajuste, verificou-se que, para cada aumento de $1 \mathrm{~mm}$ na espessura da casca, ocorre uma redução de $4,9 \%$ no rendimento da polpa de frutos e de $2,9 \%$ no rendimento do suco de maracujá.

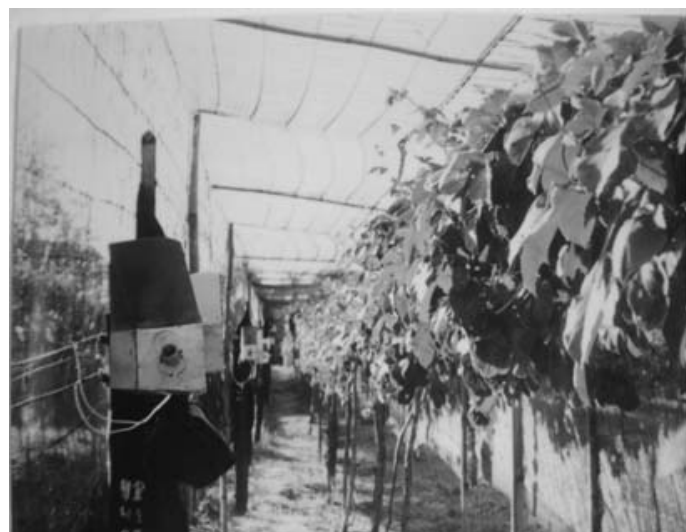

FIGURA 1 - Vista do experimento mostrando o sistema de iluminação artificial e o sombreamento. Adamantina-SP, 1997. 


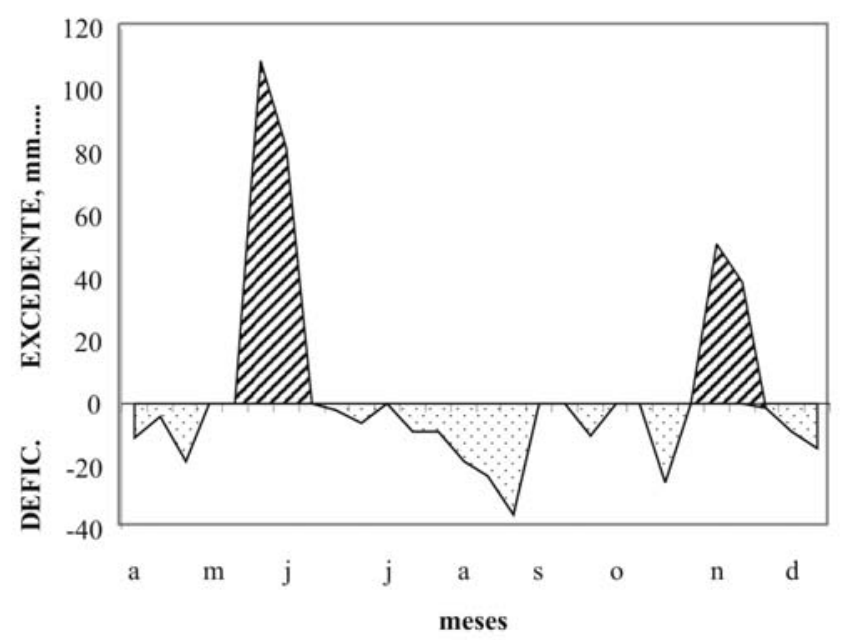

FIGURA 2 - Extrato do balanço hídrico decendial seqüencial, segundo Thornthwaite \& Mather (1955), para CAD=100 mm, referente ao período de abril a dezembro de 1997, em Adamantina-SP.
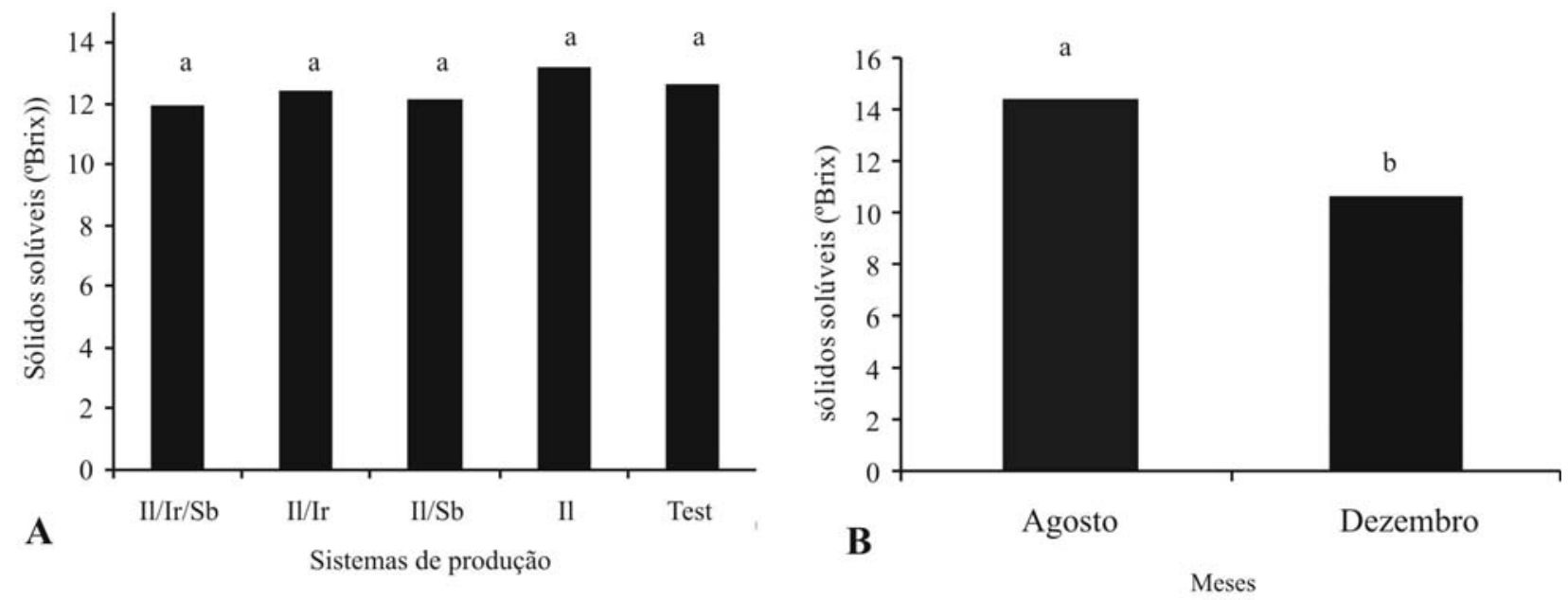

FIGURA 3 - Teor de Sólidos solúveis de frutos de maracujazeiro-amarelo submetidos à iluminação artificial (Il), irrigação (Ir) e sombreamento ( $\mathrm{Sb}$ ) (A) determinado nos meses de agosto e dezembro (B). Médias dos tratamentos seguidas por letras minúsculas distintas diferem entre si, ao nível de 5\% de probabilidade, pelo teste de Tukey. Adamantina - SP, 1997.

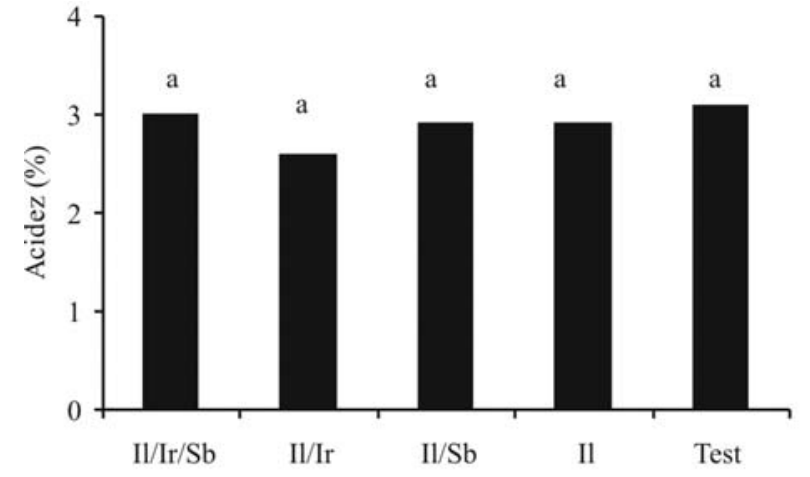

A

Sistemas de produção

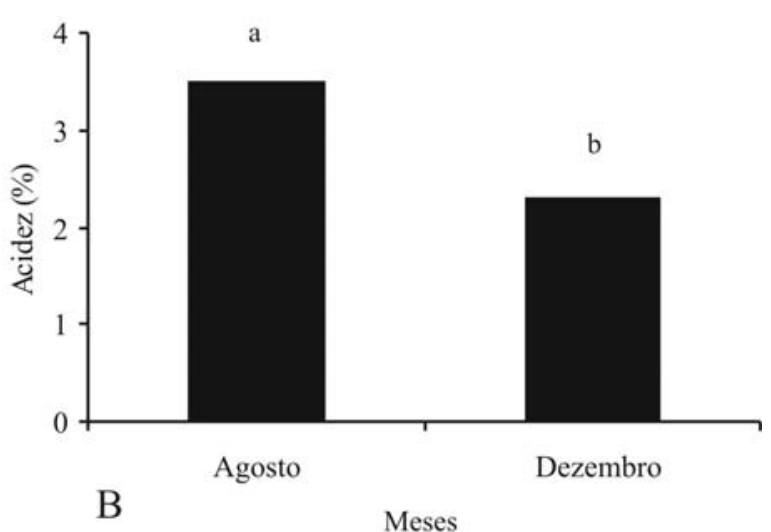

FIGURA 4 - Acidez de frutos de maracujazeiro-amarelo submetidos à iluminação artificial (Il), irrigação (Ir) e sombreamento (Sb) (A) determinado nos meses de agosto e dezembro (B). Médias dos tratamentos seguidas por letras minúsculas distintas diferem entre si, ao nível de 5\% de probabilidade, pelo teste de Tukey. Adamantina - SP, 1997. 

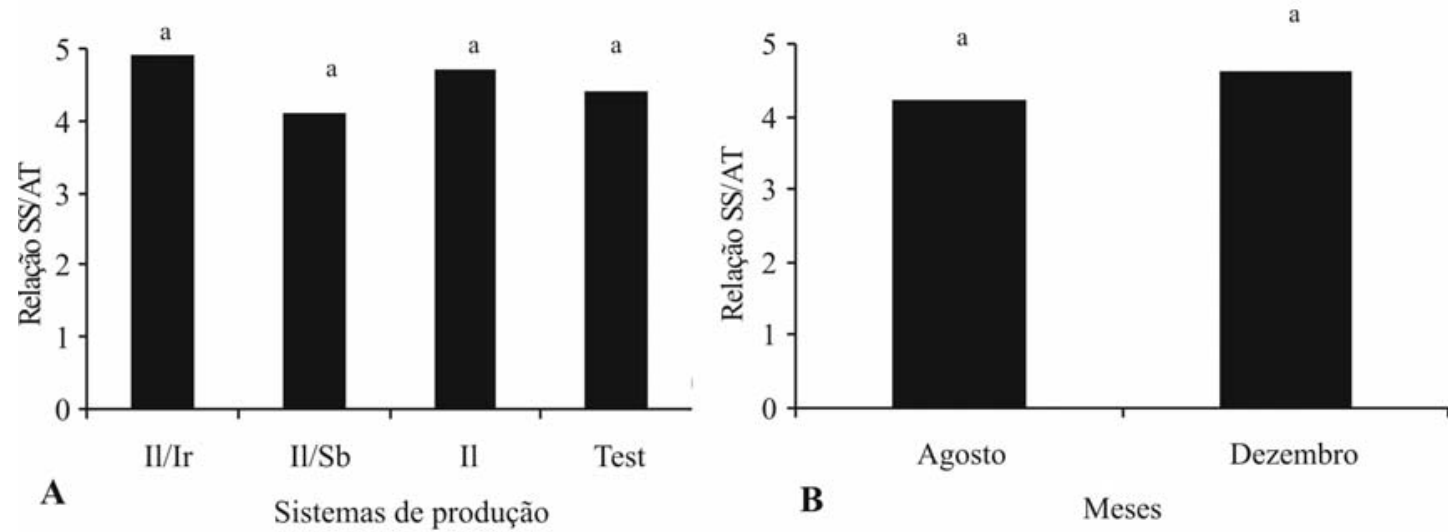

FIGURA 5 - Relação Sólidos solúveis/Acidez titulável de frutos de maracujazeiro-amarelo submetidos à iluminação artificial (Il), irrigação (Ir) e sombreamento (Sb) (A) determinado nos meses de agosto e dezembro (B). Médias dos tratamentos seguidas por letras minúsculas distintas diferem entre si, ao nível de $5 \%$ de probabilidade, pelo teste de Tukey. Adamantina - SP, 1997.

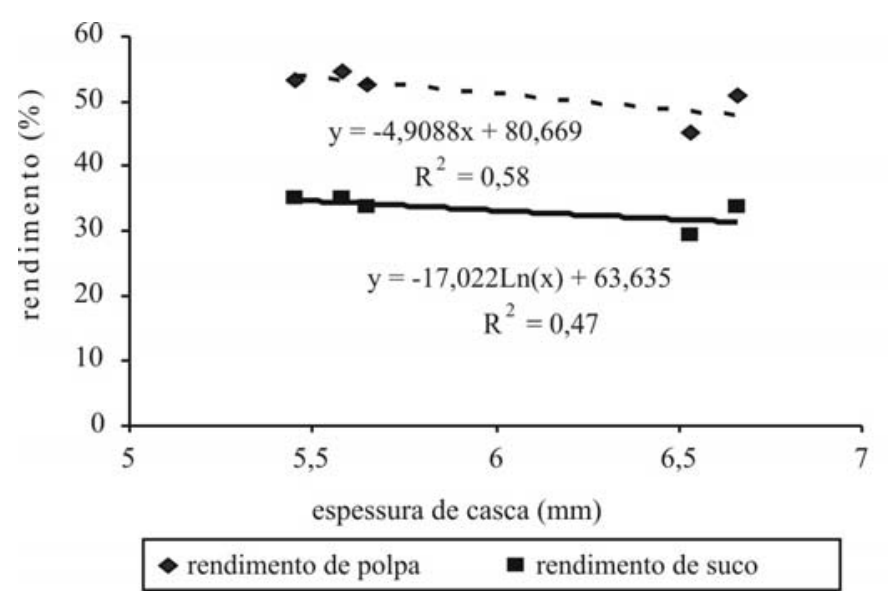

FIGURA 6 - Rendimento de polpa e de suco de maracujazeiro-amarelo submetido à iluminação artificial, irrigação e sombreamento, relacionada à espessura de casca dos frutos.

TABELA 1 - Peso, comprimento e diâmetro médios de frutos de maracujazeiro submetidos à iluminação artificial, irrigação e sombreamento - junho a novembro de 1997. Adamantina-SP.

\begin{tabular}{lccc}
\hline Tratamentos & $\begin{array}{c}\text { Peso médio } \\
\text { dos frutos }\end{array}$ & $\begin{array}{c}\text { Comprimento- } \\
\text { médio dos } \\
\text { frutos }\end{array}$ & $\begin{array}{c}\text { Diâmetro } \\
\text { médio dos } \\
\text { frutos }\end{array}$ \\
\hline Sistemas de Produção & $\mathrm{g}$ & $\mathrm{cm}$ & $\mathrm{cm}$ \\
\hline Iluminado/Irrigado/Sombreado & $149,83 \mathrm{a}$ & $7,57 \mathrm{a}$ & $6,95 \mathrm{a}$ \\
Iluminado/Irrigado & $144,53 \mathrm{a}$ & $7,72 \mathrm{a}$ & $6,87 \mathrm{a}$ \\
Iluminado/Sombreado & $144,24 \mathrm{a}$ & $7,81 \mathrm{a}$ & $6,95 \mathrm{a}$ \\
Iluminado & $145,71 \mathrm{a}$ & $7,71 \mathrm{a}$ & $6,95 \mathrm{a}$ \\
Testemunha & $145,47 \mathrm{a}$ & $7,51 \mathrm{a}$ & $6,88 \mathrm{a}$ \\
\hline Épocas de iluminação & & & \\
\hline 12 de abril & $147,57 \mathrm{~A}$ & $7,68 \mathrm{~A}$ & $6,92 \mathrm{~A}$ \\
27 de abril & $143,83 \mathrm{~A}$ & $7,67 \mathrm{~A}$ & $6,90 \mathrm{~A}$ \\
12 de maio & $146,46 \mathrm{~A}$ & $7,65 \mathrm{~A}$ & $6,94 \mathrm{~A}$ \\
\hline F sistemas de produção (s) & $0,10 \mathrm{~ns}$ & $1,50 \mathrm{~ns}$ & $0,22 \mathrm{~ns}$ \\
F épocas de iluminação (e) & $0,33 \mathrm{~ns}$ & $0,11 \mathrm{~ns}$ & $0,38 \mathrm{~ns}$ \\
F (s x e) & $0,91 \mathrm{~ns}$ & $0,86 \mathrm{~ns}$ & $1,58 \mathrm{~ns}$ \\
CV \% sistemas de produção & 16,63 & 4,52 & 4,12 \\
CV \% épocas de iluminação & 10,26 & 2,96 & 2,15 \\
Dms sistemas de produção & 17,73 & 0,27 & 0,18 \\
Dms épocas de iluminação & 11,67 & 0,18 & 0,12 \\
\hline
\end{tabular}

Médias seguidas das mesmas letras (minúsculas para sistemas de produção e maiúsculas para épocas) não diferem entre si, significativamente, ao nível de 5\% de probabilidade, pelo Teste de Tukey,

ns - não-significativo

Rev. Bras. Frutic., Jaboticabal - SP, v. 30, n. 3, p. 649-656, Setembro 2008 
TABELA 2 - Peso de fruto, peso de polpa, rendimento de polpa, espessura de casca e rendimento de suco de frutos de maracujazeiro conduzido em diferentes sistemas de cultivo, avaliados em dezembro de 1997. Adamantina-SP.

\begin{tabular}{|c|c|c|c|c|c|}
\hline Tratamentos & $\begin{array}{c}\text { Peso de fruto } \\
(\mathrm{g})\end{array}$ & $\begin{array}{c}\text { Peso de polpa } \\
\text { (g) }\end{array}$ & $\begin{array}{c}\text { Rendimento de } \\
\text { polpa (\%) }\end{array}$ & $\begin{array}{c}\text { Espessura de casca } \\
(\mathrm{mm})\end{array}$ & $\begin{array}{c}\text { Rendimento de } \\
\text { suco (\%) }\end{array}$ \\
\hline \multicolumn{6}{|l|}{ Sistemas de Produção-* } \\
\hline Iluminado/Irrigado/Sombreado & $173,58 \mathrm{a}$ & $89,62 \mathrm{a}$ & $50,93 \mathrm{a}$ & $6,66 \mathrm{a}$ & $33,59 \mathrm{ab}$ \\
\hline Iluminado/Irrigado & $155,76 \mathrm{ab}$ & $85,12 \mathrm{a}$ & $54,65 \mathrm{a}$ & $5,58 \mathrm{bc}$ & $34,91 \mathrm{a}$ \\
\hline Iluminado/Sombreado & $149,87 \mathrm{ab}$ & $67,22 \mathrm{~b}$ & $45,21 \mathrm{~b}$ & $6,53 \mathrm{ab}$ & $29,25 \mathrm{~b}$ \\
\hline Iluminado & $147,27 a b$ & $78,26 \mathrm{ab}$ & $53,37 \mathrm{a}$ & $5,45 \mathrm{c}$ & $34,94 \mathrm{a}$ \\
\hline Testemunha & $131,66 \mathrm{~b}$ & $69,14 \mathrm{~b}$ & $52,56 \mathrm{a}$ & $5,65 \mathrm{bc}$ & $33,67 \mathrm{a}$ \\
\hline \multicolumn{6}{|l|}{ Épocas de iluminação } \\
\hline 12 de abril & $154,90 \mathrm{~A}$ & $82,76 \mathrm{~A}$ & $53,01 \mathrm{~A}$ & $5,92 \mathrm{~A}$ & $33,88 \mathrm{~A}$ \\
\hline 27 de abril & $144,54 \mathrm{~A}$ & $72,71 \mathrm{~B}$ & $50,36 \mathrm{~A}$ & $5,83 \mathrm{~A}$ & $32,42 \mathrm{~A}$ \\
\hline 12 de maio & $155,44 \mathrm{~A}$ & $78,14 \mathrm{AB}$ & $50,66 \mathrm{~A}$ & $6,18 \mathrm{~A}$ & $33,51 \mathrm{~A}$ \\
\hline F sistemas de produção (s) & $6,40 * *$ & $11,77 * *$ & $4,54 *$ & $13,63^{* *}$ & $4,05 *$ \\
\hline F épocas de iluminação (e) & $1,38 \mathrm{~ns}$ & $4,52 *$ & $1,96 \mathrm{~ns}$ & $1,03 \mathrm{~ns}$ & $0,84 \mathrm{~ns}$ \\
\hline $\mathrm{F}(\mathrm{s} \times \mathrm{e})$ & $0,79 \mathrm{~ns}$ & $0,86 \mathrm{~ns}$ & $1,68 \mathrm{~ns}$ & $0,45 \mathrm{~ns}$ & $1,18 \mathrm{~ns}$ \\
\hline CV \% sistemas de produção & 13,69 & 12,64 & 11,67 & 8,99 & 12,11 \\
\hline CV \% épocas de iluminação & 15,44 & 13,59 & 9,00 & 13,44 & 11,14 \\
\hline Dms sistemas de produção & 27,72 & 12,53 & 5,47 & 0,95 & 4,39 \\
\hline Dms épocas de iluminação & 18,25 & 8,25 & 3,60 & 0,63 & 2,89 \\
\hline
\end{tabular}

Médias seguidas de letras distintas diferem entre si, significativamente, ao nível de $5 \%$ de probabilidade, pelo Teste de Tukey. ns - não-significativo

* significativo ao nível de 5\%

** significativo ao nível de $1 \%$

\section{CONCLUSÕES}

1- A iluminação artificial não altera o comprimento e o diâmetro médio, o teor de sólidos solúveis e a acidez de frutos de maracujazeiro-amarelo. Quando associada com irrigação e sombreamento, aumenta o peso médio dos frutos, o peso da polpa e a espessura da casca.

2- A redução da iluminação natural prejudica o rendimento de polpa e de suco de maracujá-amarelo.

\section{REFERÊNCIAS}

ALBRIGO, G. Influências ambientais no desenvolvimento de frutos cítricos. In: SEMINÁRIO INTERNACIONAL DE CITROS - FISIOLOGIA, 2., 1992, Bebedouro-SP. Anais... Campinas: Fundação Cargill, 1992.p.100-105.

AGRIANUAL 2007: anuário da agricultura brasileira. São Paulo: FNP Consultoria e Comércio, 2006. p.387-394.

BORGES,A.L.; RODRIGUES, M.G.V., LIMA,A.deA.,ALMEIDA, I.E., CALDAS, R.C. Produtividade e qualidade de maracujáamarelo irrigado, adubado com nitrogênio e potássio. Revista Brasileira de Fruticultura, Jaboticabal, v.25, n.2, p.259-262, 2003.

CAVICHIOLI, J.C.; RUGGIERO, C.; VOLPE, C.A.; PAULO, E.M.; FAGUNDES, J.L.; KASAI, F.S. Florescimento e frutificação do maracujazeiro-amarelo submetido à iluminação artificial, irrigação e sombreamento. Revista Brasileira de Fruticultura, Jaboticabal, v.28, n.1, p.92-96, 2006.
COSTA, J.R.M.; LIMA, C.A. de A.; LIMA, E.D.P. de A.; CAVALCANTE, L.F.; OLIVEIRA, F.K.D. de. Caracterização dos frutos de maracujá-amarelo irrigados com água salina. Revista Brasileira de Engenharia Agrícola e Ambiental, Campina Grande, v.5, n.1, p.143-146, 2001.

FORTALEZA, J.M.; PEIXOTO, J.R.; JUNQUEIRA, N.T.V.; OLIVEIRA, A.T. de; RANGEL, L.E.P. Características físicas e químicas em nove genótipos de maracujá-azedo cultivado sob três níveis de adubação potássica. Revista Brasileira de Fruticultura, Jaboticabal, v. 27, n.1, p. 124-127, 2005.

FRACARO, A.A. Produção de suco e polpa de maracujá. 2004. Disponível em: $<$ http://www.todafruta.com.br $>$. Acesso: 25 maio 2007.

FRANCIS, C. A. Effective day lenghts for the study of photoperiod sensitive reactions in plants. Agronomy Journal, Madison, v.62, n.6, p.790-3, 1970.

IES. Lighting handbook. Nonvisual effects of radiant energy on plants. In: __ Lighting handbook. New York, 1981. p.19-31.

LOPES, P.R. Efeitos da irrigação localizada e cobertura do solo na produtividade do maracujazeiro Passiflora edulis Sims $\mathrm{f}$. flavicarpa Deg. Jaboticabal, 1995. 70 f. Dissertação (Mestrado em Agronomia) - Faculdade de Ciências Agrárias e Veterinárias, Universidade Estadual Paulista, Jaboticabal, 1995.

MALAVOLTA, E.; VITTI, G.C.; OLIVEIRA, S.A. de. Avaliação do estado nutricional das plantas: princípios e aplicações. Piracicaba: Potafos, 1989.201p. 
MELETTI, L. M. M. A cultura do maracujazeiro em São Paulo. O Agronômico, Campinas, vol. 53, n.1,p. 18-20, 2001.

MENZEL, C. M.; SIMPSON, D. R.; DOWLING, A. J. Water relations in passion fruit: effect of moisture stress on growth, flowering and nutrient uptake. Scientia Horticulturae, Amsterdam, v.29, p.239-49, 1986.

NASCIMENTO, T. B. do. Qualidade do maracujá-amarelo produzido em diferentes épocas no Sul de Minas Gerais, 1996. 56 f. Dissertação (Mestrado em Fitotecnia) -Universidade Federal de Lavras, Lavras, 1996.

PHILIPS. Artificial lighting in horticulture. In: Philips lighting. Netherlands, 1989. 40p.

PIERRÔ, A. Gosto Bom. Cultivar Hortaliças e Frutas, n. 14, p.1012, 2002.

PIZAJUNIOR, C. de T. Cultura do maracujá. Campinas: Secretaria da Agricultura e Abastecimento, 1993. 71p.

RASMUSSEN, G.K. et al. The organic acid content of Valencia oranges from four location in the United States. Proceedings of the American Society Horticultural Science, Alexandria, v.89, p.206-210, 1966.
RITZINGER, R.; MANICA, I.; RIBOLDI, J. Efeito do espaçamento e da época de colheita sobre a qualidade do maracujá-amarelo. Pesquisa Agropecuária Brasileira, Brasília, v.24, n.2, p.241-245. 1989.

SJOSTROM, G.; ROSA, J. F. L. Estudo sobre as características físicas e comparação química do maracujá-amarelo, Passiflora edulis f. flavicarpa Deg. cultivado no município de Entre Rios, Bahia. In: CONGRESSO BRASILEIRO DE FRUTICULTURA, 4., 1977, Salvador. Anais... Caçador: Sociedade Brasileira de Fruticultura, 1978. p.265-73.

TAIZ, L.; ZEIGER, E. The Control of Flowering. In: Plant physiology. Redwood City: The Benjamin/Cummings, 1991. cap.21, p.513-531.

TEIXEIRA, D.M.M.; OLITTA, A.F.L.; VASCONCELOS, L.A.B.C. de. Efeito de vários níveis de fertirrigação na cultura do maracujazeiro-amarelo (Passiflora edulis var. flavicarpa). Engenharia Rural, Piracicaba, v.1, n.1, p.1-76. 1990.

THORNTHWAITE, C. W.; MATHER, J. R. The water balance. Centerton:N.J, Drexel Institute of Technology, 1955. 104 p.

UTSUNOMIYA, N. Effect of temperature on shoot growth, flowering and fruit growth of purple passionfruit (Passiflora edulis Sims var. edulis). Scientia Horticulturae, Amsterdam, v.52, n.1/2, p.63-68, 1992. 